\title{
Laser Photobiomodulation and Antimicrobial Photodynamic Therapy in the Treatment of Ovine Otitis
}

\author{
Marcus Vinícius Alves da Silva', Manoel Luiz Ferreira', Ana Flávia Ribeiro Machado Michel'2, \\ Thiago Santos Ribeiro ${ }^{3}$, Vinícius de Oliveira Costa Souza ${ }^{3}$, Jacson Vale Leite ${ }^{3}$, \\ Guilherme Oliveira da Silva ${ }^{3} \&$ Fernando Alzamora Filho²
}

\begin{abstract}
Background: Otitis is a severe inflammation of the skin of the auditory canal which can impact animals of all ages. In sheep, this disease can occur in isolated cases or in the entire flock. Laser photobiomodulation can be used in combination with medication or as single therapy and the effects are analgesia, modulation of the inflammatory process, edema reduction, tissue restoration and stimulation of local microcirculation. Antimicrobial photodynamic therapy stands out as a promising alternative to antimicrobial drugs for the treatment of localized infections. This study aimed to report the use of laser phototherapies on a sheep with bacterial otitis.

Case: A case of bacterial otitis in a 4-year-old sheep, Dorper, was treated at the Veterinary Hospital of the State University of Santa Cruz. In the anamnesis, the owner reported that the patient presented crusts in the auricular pavilions, and had been medicated with oxytetracycline $20 \%$, administered intramuscularly, for two days and the crusts cleaned with iodine $10 \%$, but the animal did not present clinical improvement. On physical examination, the animal presented constant head swaying, edema of the ears, otalgia, enlarged parotid lymph nodes and ear wounds. No ear discharge was observed, and the initial diagnosis was aural hematoma. The treatment prescribed was laser photobiomodulation for three consecutive days. The lesions were irradiated with a diode laser with a power of $0.1 \mathrm{~W}$, irradiance of $3.5 \mathrm{~W} / \mathrm{cm}^{2}$, continuous emission, spot area of $0.028 \mathrm{~cm}^{2}$, wavelength of $808 \mathrm{~nm}$, energy of $4 \mathrm{~J} /$ point, and fluency/point of $142.8 \mathrm{~J} / \mathrm{cm}^{2}$, with seven points on the external surface and four points on the internal surface of both ears. Two points were also targeted on the parotid lymph nodes with infrared laser $(\lambda=808 \mathrm{~nm})$, with energy of $2 \mathrm{~J} /$ point. On the fourth day of hospitalization, there was a reduction in lesions, decreased edema and absence of pain and on the sixth day of hospitalization, the patient presented mucopurulent otorrhea. The material from the auricular pavilions was collected for cytological examination, confirming the clinical diagnosis of bacterial otitis. Two sessions of Antimicrobial Photodynamic Therapy (aPDT) were performed with an interval of 48 hours, with application of $0.01 \%$ methylene blue, pre-irradiation time of five minutes and irradiation with diode laser with a power of $0.1 \mathrm{~W}, 660 \mathrm{~nm}$ wavelength and 9J/point energy. On the 10 th day after the start of the treatment, there was no pain, healing of ear wounds, and no otorrhea. An additional photobiomodulation session was performed on the unhealed wounds in the auditory canal with red laser $(\lambda=660 \mathrm{~nm})$, on 5 points with an energy of $1 \mathrm{~J} /$ point. On the 15th day, the left ear was healed and the right ear presented otorrhea, and a further session of aPDT was performed. On the 17th day after starting treatment there was no secretion and all lesions were healed. The patient was subsequently monitored for one month, showing no change or relapse.

Discussion: Laser photobiomodulation treatment and antimicrobial photodynamic therapy were efficient in treating bacterial otitis without the use of antibiotics, promoting clinical improvement and patient well-being, making it an alternative to conventional treatment. After searches on the Pubmed, Scielo and Escopus databases using photobiomodulation and antimicrobial photodynamic therapy in sheep otitis as descriptors, this is believed to be the first report on the use of laser phototherapy in sheep otitis. Further studies are needed to establish the dosimetry and frequency of the sessions, as, besides considering animal well-being, this species is an excellent model for human experimentation.
\end{abstract}

Keywords: ear infection, photoinactivation, laser therapy, small ruminants.

DOI: $10.22456 / 1679-9216.106149$

Received: 14 November 2020

Accepted: 4 March 2021

Published: 15 May 2021

${ }^{1}$ Experimental Surgery Center, Department of Surgery, Faculty of Medicine. Federal University of Rio de Janeiro (UFRJ), Rio de Janeiro, RJ, Brazil. ${ }^{2}$ Department of Agrarian and Environmental Sciences, Veterinary Medicine Program Course \& ${ }^{3}$ Veterinary Medicine Course of the State University of Santa Cruz (UESC), Ilhéus, BA, Brazil. CORRESPONDENCE: F. Alzamora Filho [fafilho@ uesc.br]. State University of Santa Cruz (UESC). Rodovia Jorge Amado, Km 16. CEP 45662-900 Ilhéus, BA, Brazil. 


\section{INTRODUCTION}

Otitis is a severe inflammation of the auditory canal which can impact animals of all ages. In sheep, this disease can occur in isolated cases or in the entire flock. Foreign bodies and various infections can cause irritation in the ear and intense pruritus, resulting in head shaking, friction of the ear against objects and it can also progress to otitis media or otitis interna [12,21]. There are several treatments using anti-inflammatories, antibiotics, and antifungals, but they can become ineffective, causing economic losses $[10,15,17]$.

Laser photobiomodulation (LPBM) can be used alone or associated with other therapies and the effects on the injured tissue are analgesia, modulation of the inflammatory process, edema reduction, tissue restoration and stimulation of local microcirculation $[3,13]$. LPBM is based on photophysical and photochemical principles and has been used and tested in the treatment of several lesions and diseases [4,8,19,23,24].

Antimicrobial photodynamic therapy (aPDT) stands out as a promising alternative to antimicrobial drugs for the treatment of localized infections $[7,18,26]$. This therapy involves the use of photosensitizers, which, with specific wavelength and molecular oxygen, directly affect gram-negative and gram-positive bacteria without affecting the host cells, resulting in the formation of reactive oxygen species and singlet oxygen production, which destroys microorganisms due to structural changes fundamental to their survival $[1,2,5,6,13,18]$. The present study aimed to report the use of laser phototherapies in a sheep with bacterial otitis.

\section{CASE}

A case of bacterial otitis in a 4-year-old sheep, Droper, from the city of Ilhéus-Bahia, Brazil, was treated at the Veterinary Hospital of the State University of Santa Cruz (UESC). Reared on rotational pasture of Panicum maximum, in the anamnesis, the owner reported that the patient presented crusts in the auricular pavilions, and had been medicated with oxytetracycline $20 \%$ (Oxitetra 20\% ${ }^{\circledR 1}$ ), administered intramuscularly, for two days and the crusts cleaned with iodine $10 \%$ (Riodeine $10 \%{ }^{\circledR 2}$ ), but the animal did not show clinical improvement. On physical examination, the animal presented constant head swaying, edema of the ears, otalgia, enlarged parotid lymph nodes and wounds in the auricular pavilion (Figure 1A). No secretion was observed in the auricular pavilion and the initial diagnosis was aural hematoma.

The treatment prescribed was laser photobiomodulation for three consecutive days. The lesions were irradiated with a diode laser with a power output of $0.1 \mathrm{~W}$, irradiance of $3.5 \mathrm{~W} / \mathrm{cm}^{2}$, continuous emission, spot area of $0.028 \mathrm{~cm}^{2}$, wavelength of $808 \mathrm{~nm}$, energy

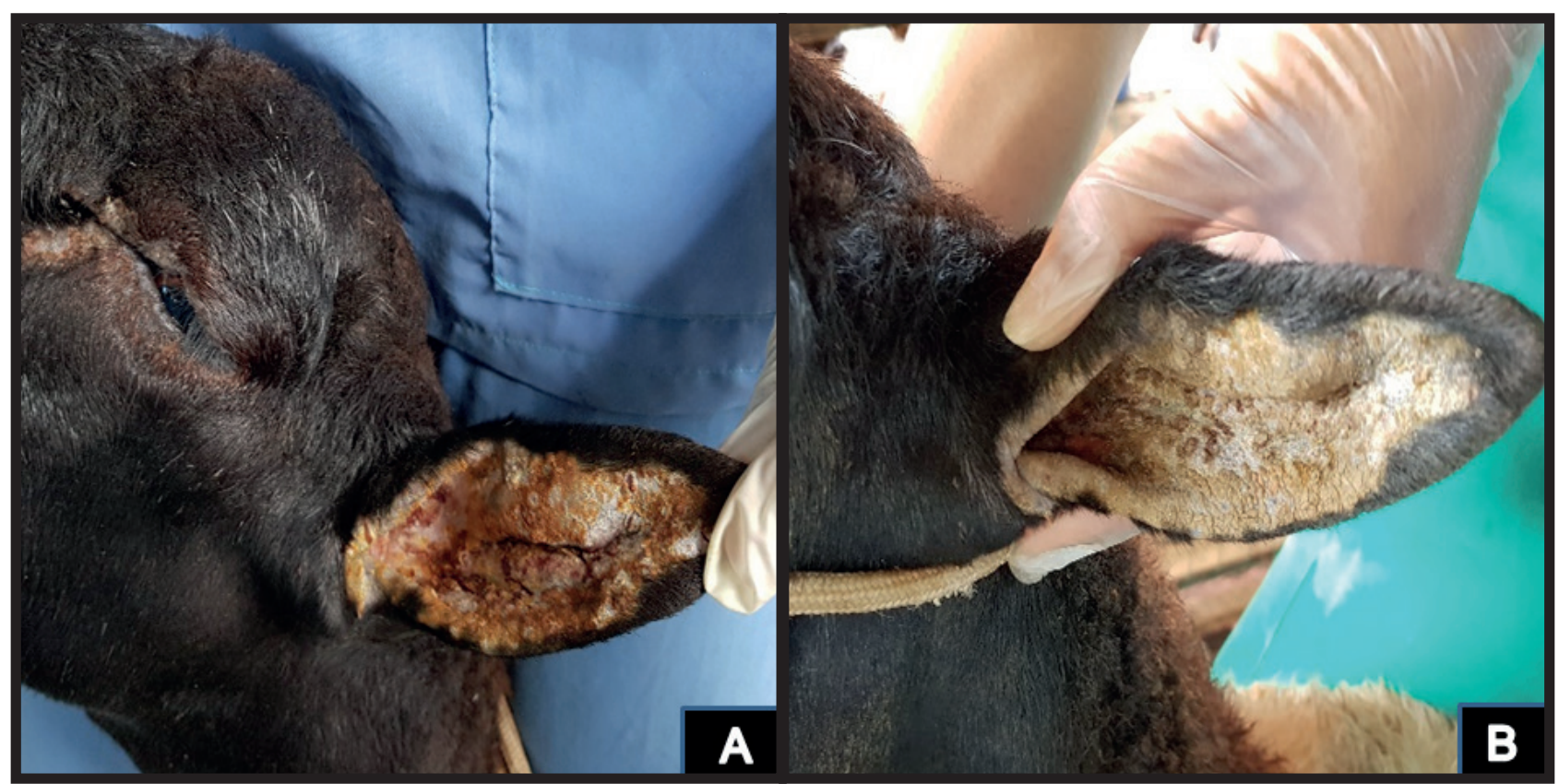

Figure 1. A- Sheep with swollen regions and crusts in the ear, on the first day of treatment. B- Animal showed a reduction in edema and crusts on the third day after starting the treatment. [Source: Fernando Alzamora Filho]. 


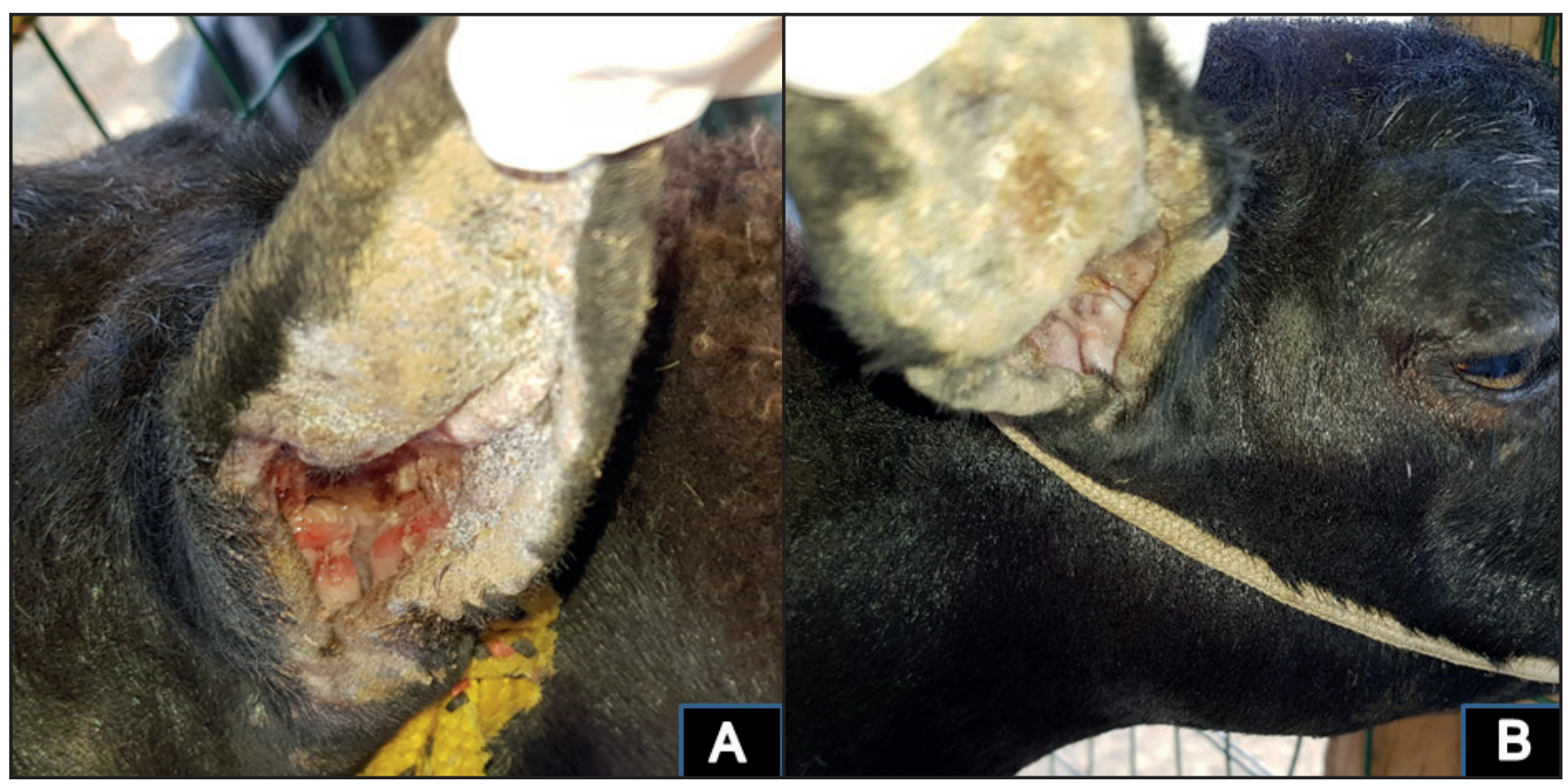

Figure 2. A- Animal on the sixth day after the beginning of the treatment, with reduced edema, crusts and presence of otorrhea in the ear (white arrow). B- Sheep showing otitis resolution on the 17th day of treatment. [Source: Fernando Alzamora Filho].

of $4 \mathrm{~J} /$ point, and fluence/point of $142.8 \mathrm{~J} / \mathrm{cm}^{2}$, with seven points on the external surface and four points on the internal surface of both ears. Two points were also targeted on the parotid lymph nodes with infrared laser $(\lambda=808 \mathrm{~nm})$, with energy of $2 \mathrm{~J} /$ point. On the fourth day of hospitalization, there was a reduction in lesions, decreased edema (Figure 1B) and no pain, and on the sixth day of hospitalization, the patient presented mucopurulent otorrhea (Figure 2A). The material from the auricular pavilions was collected for cytological examination, confirming the clinical diagnosis of bacterial otitis.

Two sessions of Antimicrobial Photodynamic Therapy (aPDT) were performed with an interval of $48 \mathrm{~h}$, with application of $0.01 \%$ methylene blue, pre-irradiation time of $5 \mathrm{~min}$ and irradiation with diode laser with a power output of $0.1 \mathrm{~W}, 660 \mathrm{~nm}$ wavelength and $9 \mathrm{~J} /$ point energy. On the 10th day after the start of the treatment, there was no pain, healing of ear wounds, and no otorrhea were observed. An additional photobiomodulation session was performed on the unhealed wounds in the auditory canal with red laser $(\lambda=660 \mathrm{~nm})$, on 5 points with an energy of $1 \mathrm{~J} /$ point. On the 15th day, the left ear was cured and the right ear presented otorrhea, and a new session of aPDT was performed. On the 17 th day after starting the treatment there was no secretion and lesions were healed (Figure 2B). The patient was monitored for 1 month, presenting no changes or recurrences.

\section{DISCUSSION}

The sheep treated with signs and symptoms of otitis, confirmed in the anamnesis, was the only animal affected by the disease, validating the observations that related to an isolated case of an animal from the flock of the property [14].

The signs presented in relation to the auricular pavilion were edema, crusts, intense pruritus, excessive head movement, and aural hematoma due to the constant friction of the ear with the head swinging or trauma from knocking against objects. Due to the extent of the symptoms and the edema, it was impossible to examine the auditory canal in the initial examination, as it was obstructed, agreeing with the findings of auricular hematoma [16].

Inflammation and chronic infections often become difficult to treat, as in the case of this animal, which had already been wrongly treated with $10 \%$ iodine solution as an antiseptic in the auricular pavilion, which can aggravate existing lesions due to a chemical lesion by iodine. Furthermore, the use of $20 \%$ oxytetracycline (Oxitetra 20\% ${ }^{\circledR}$ ) in sub-therapeutic doses and the short treatment period led to an ineffective result, as the treatment of otitis media is specific antibiotics used against the frequently isolated pathogens spread in the middle and inner ear, and the duration of therapy is influenced by the chronicity of the disease as well as the pathogens involved, ranging from five days to several weeks $[11,17]$. 
Due to aural hematoma and otalgia, photobiomodulation with infrared laser $(808 \mathrm{~nm})$ was initially prescribed for the treatment of inflammation and edema. According to [28], the appropriate choice of wavelength, energy density, point energy, type of emission and form of application are essential to obtain an efficient biological effect, such as reduced inflammation by decreasing chemical inflammatory mediators, like prostaglandin $\mathrm{E} 2$, leukocytes and tumor necrosis factor (TNF- $\alpha$ ), and by increasing anti-inflammatory mediators such as interleukin 10. The analgesic action of laser therapy can be explained by the modulation of inflammation, alteration of the nerve conduction of peripheral neurons and release of endogenous endorphins [9,20]. The increase of microcirculation at the irradiation site results in changes in capillary hydrostatic pressure, with improved lymphatic circulation and reabsorption of edema [22]. The present report observed a rapid reduction in edema and absence of otalgia, as per the scientific literature.

The cytology reported a large amount of amorphous basophilic debris and bacteria (cocci and rods) adhered to epithelial cells, characterizing bacterial otitis, which corroborates the choice of antimicrobial photodynamic therapy in the treatment due to bactericidal action through the formation of reactive species of oxygen and singlet oxygen [6,27]. Furthermore, as a result of the emergence of diseases caused by multidrug-resistant microorganisms in veterinary medicine, due to the excessive use of antibiotics, new treatments should be developed as an alternative to conventional treatment [27].

As observed in a previous study [25], chronic otitis media leads to destruction of the middle ear and the treatments currently available provide limited relief, which was not observed in the treatment prescribed in this case, absence of pain being observed within a few days. The results observed provided a more rapid recovery in relation to treatment with local, systemic antibiotics, with resolution of otitis in 7 laser phototherapy sessions. On the 17 th day after the beginning of treatment, there was an absence of secretion and healed lesions, and the animal was considered cured by the team responsible for the sheep's treatment. The patient was subsequently monitored for 1 month and showed no change or relapse.

Treatment with LPBM and aPDT were efficient in the treatment of bacterial otitis without the use of antibiotics, promoting clinical improvement and patient well-being, providing an alternative to conventional treatment. Depending on the severity of the injury, as in otitis interna, laser photobiomodulation can be associated with conventional therapies, such as systemic antibiotic therapy. The choices depend on clinical and complementary exams for the diagnosis, in addition to the experience of the Veterinarian with the use of low-intensity laser. After comprehensive review of major commercial databases, this is believed to be the first report on the use of laser phototherapy in sheep otitis. Further studies are needed to establish the dosimetry and frequency of the sessions, because, besides considering animal well-being, this species is an excellent model for human experimentation.

\section{MANUFACTURERS}

${ }^{1}$ VitalFarma Ltda. São Sebastião do Paraíso, MG, Brazil. ${ }^{2}$ Rioquímica. São José do Rio Preto, SP, Brazil.

Declaration of interest. The authors report no conflicts of interest. The authors alone are responsible for the content and writing of the paper.

\section{REFERENCES}

1 Ahad A., Lamba A.K., Faraz F., Tandon S., Chawla K. \& Yadav N. 2016. Effect of antimicrobial photodynamic therapy as an adjunct to nonsurgical treatment of deep periodontal pockets: a clinical study. Journal of Lasers in Medical Sciences. 7(4): 220-226.

2 Alzamora Filho F., Cavalcante M.P., Rocha N.M.A., Souza V.O.C., Ribeiro T.S., Brito T.M. \& Reis L.G.R. 2018. Use of photodynamic antimicrobial therapy and laser therapy in the treatment of ovine infectious dermatitis. Revista Acadêmica Ciência Animal. 16: e163501.

3 Andrade F.S.S.D., Clark R.M.O. \& Ferreira M.L. 2014. Efeitos da laserterapia de baixa potência na cicatrização de feridas cutâneas. Revista do Colégio Brasileiro de Cirurgiões. 41(2): 129-133.

4 Arslan H., Doganay E., Karatas E., Ünlü M.A. \& Ahmed H.M.A. 2017. Effect of low-level laser therapy on postoperative pain after root canal retreatment: a preliminar placebo-controlled, triple-blind, randomized clinical trial. Journal of Endodontics. 43(11): 1765-1769. 
5 Azaripour A., Dittrich S., Van Noorden C.J.F. \& Willershausen B. 2018. Efficacy of photodynamic therapy as adjunct treatment of chronic periodontitis: a systematic review and meta-analysis. Lasers in Medical Science. 33(2): 407-423.

6 Bagnato V.S., Kurachi C., Blanco K.C. \& Inada N.M. 2017. Antimicrobial Photodynamic Therapy. In: Hamblin M.R., Sousa M.V.P. \& Agrawal T. (Eds). Handbook of Low-Level Laser Therapy. Singapore: Pan Stanford Publishing, pp.273-283.

7 Bahar A.A. \& Ren D. 2013. Antimicrobial peptides. Pharmaceuticals. 6(12): 1543-1475.

8 Baltzer A.W.A., Stosch D., Seidel F. \& Ostapczuk M.S. 2017. Low level laser therapy: a narrative literature review on the efficacy in the treatment of rheumatic orthopaedic conditions. Zeitschrift für Rheumatologie. 76: 806-812.

9 Basford J.R., Hallman H.O., Matsumoto J.Y., Moyer S.K., Buss J.M. \& Baxter G.D. 1993. Effects of 830-nm continuous wave laser diode irradiation on median nerve function in normal subjects. Lasers in Surgery and Medicine. 13(6): 597-604.

10 Bernier Gosselin V., Francoz D., Babkine M., Desrochers A., Nichols S., Doré E., Bédard C., Parent J., Fairbrother J.H. \& Fecteau G. 2012. A retrospective study of 29 cases of otitis media/interna in dairy calves. The Canadian Veterinary Journal. 53(9): 957-962.

11 Bertone I., Bellino C., Alborali G.L., Cagnasso A., Cagnotti G., Dappiano E., Lizzi M., Miciletta M., Ramacciotti A., Gianella P. \& D'Angelo A. 2015. Clinical-pathological findings of otitis media and media-interna in calves and (clinical) evaluation of a standardized therapeutic protocol. BMC Veterinary Research. 11: 297.

12 Boileau M.J. \& Gilliam J. 2017. Brainstem and cranial nerve disorders of ruminants. Veterinary Clinics of North America Food Animal Practice. 33(1): 67-99.

13 Chavantes M.C. \& Tomimura S. 2009. Classificação dos Lasers. In: Chavantes M.C. (Ed). Laser em Bio-Medicina: Princípios e Prática. São Paulo: Atheneu, pp.51-60.

14 Constable L. \& Butler I. 1982. Microbial Flora in chronic otitis media. Journal of Infection. 5: 57-60

15 Constantin T., Houshaimy K. \& Togoe D. 2016. Medical and Surgical Management of Otitis in Sheep-case Report. Agriculture and Agricultural Science Procedia 10: 390-395.

16 Eurides D., Souza L.A., Oliveira B.J.N.A. \& Souza L.A.F. 2008. Drenagem de otohematoma em cães. Revista Portuguesa de Ciências Veterinárias. 103(565-566): 59-63

17 Francoz D., Fecteau G., Desrochers A. \& Fortin M. 2004. Otitis media in dairy calves: a retroscpective study of 15 cases (1987 to 2002). The Canadian Veterinary Journal. 45(8): 661-666.

18 Giuliani F., Martinelli M., Cocchi A., Arbia D., Fantetti L. \& Roncucci G. 2010. In vitro resistance selection studies of RLP068/CI, a new Zn (II) phthalocyanine suitable for antimicrobial photodynamic therapy. Antimicrobial Agents and Chemotherapy. 54(2): 637-642.

19 Glazov G., Yelland M. \& Emery J. 2016. Low-level laser therapy for chronic non-specific low back pain: a metaanalysis of randomised controlled trials. Acupuncture in Medicine. 34(5): 328-341.

20 Laakso L., Richardson C. \& Cramond T. 1993. Factors affecting Low Level Laser Therapy. Australian Journal of Physiotherapy. 39(2): 95-99.

21 Linhart R.D. \& Brumbaugh G.W. 2019. Control of bovine respiratory disease, with and without co-morbidity by otitis media, in dairy heifers comparing gamithromycin, tulathromycin, or no medication at a comercial development facility. Journal of Dairy Science. 102(6): 5501-5510.

22 Lins R.D.A.U., Dantas E.M., Lucena K.C.R., Catão M.C.V., Granville-Garcia A.F. \& Carvalho Neto L.G. 2010. Biostimulation effects of low-power laser in the repair process. Anais Brasileiro de Dermatologia. 85(6): 849-855.

23 Pallotta R.C., Bjordal J.M., Frigo L., Leal E.C., Teixeira S., Marcos R.L., Ramos L., Messias F.M. \& LopesMartins R.A. 2012. Infrared (810-nm) low-level laser therapy on rat experimental Knee inflammation. Lasers in Medical Science. 27(1): 71-78.

24 Peng Z., Chen X.Q., Gong S.S. \& Chen C.F. 2014. Low-level laser therapy for tinnitus. Cochrane database of systematic reviews. 4: CD009811. DOI: 10.1002/14651858.CD009811

25 Pohl F., Schuon R.A., Miller F., Kampmann A., Bültmann E., Hartmann C., Lenarz T. \& Paasche G. 2018. Stenting the Eustachian tube to treat chronic otitis media - a feasibility study in sheep. Head Face Medicine. 14: 8. 
26 Sellera F.P., Gargano R.G., Libera A.M.P.D., Benesi F.J., Azedo M.R., de Sá L.R.M., Ribeiro M.S., Silva Baptista M. \& Pogliani F.C. 2016. Antimicrobial photodynamic therapy for caseous lymphadenitis abscesses in sheep: report of ten cases. Photodiagnosis and Photodynamic Therapy. 13: 120-122.

27 Scherer K.M., Bisby R.H., Botchway S.W. \& Parker A.W. 2016. New approaches to photodynamic therapic from types I, II and III to type IV using one or more photons. Anti-cancer Agents in Medicinal Chemistry. 17(2): 171-189.

28 Sousa M.V.P. 2016. What is low-level laser (light) therapy? In: Hamblin M.R., Sousa M.V.P. \& Agrawal T. (Eds). Handbook of Low-Level Laser Therapy. New York: Pan Stanford, pp.1-16. 